International Journal of Engineering \& Technology, $7(2.32)(2018) 125-130$
International Journal of Engineering \& Technology
Website: www.sciencepubco.com/index.php/IJET
Research paper

\title{
Simultaneous Scheduling Through Heuristic Algorithms
}

\author{
M. Nageswara Rao ${ }^{1}$, K. Lokesh ${ }^{2}$, V. Harish ${ }^{3}$, Ch. Sai Bharath ${ }^{4}$, Y. Venkatesh ${ }^{5}$, Vara Kumari. $\mathrm{S}^{6}$ \\ 1, 2,3,4,5 Mechanical Department, KLEF, Guntur, India \\ ${ }^{6}$ ECE Department, KLEF, Guntur, India \\ *Corresponding Author E-Mail: Medikondu@Kluniversity.In
}

\begin{abstract}
Flexible Manufacturing System (FMS) is a compli-cated system because of work environments, recu-peration frameworks, mechanized putting away, and material dealing with gadgets like robots and AGVs. In this paper, an endeavor is made by con-sidering both the machine and vehicle planning angles in FMS for minimization of the make trav-erse. Game plan is ensnared with the arrangement of incomplete assets to assignments in finished time. It is like Information-gathering process. It is related with the cost, operations, time and several objectives of the industry. In this work, RAPID ACCESS (RA) heuristic algorithm is adopted to solve the scheduling problems in FMS. Eighty, two problems and their existing solutions with different approaches are examined. The RA heuristic algo-rithm provides better solutions with less computa-tional time.
\end{abstract}

Keywords: Flexible Manufacturing System, Heuristic Algo-rithms, makespan, AGVs

\section{Introduction}

Scheduling is an Information-gathering process mostly used in several manufacturing and maintenance industries. Here, it deals with optimizing one or more objectives by allocation of resources to tasks for the specified time periods. There are different forms of resources and tasks in industries. The machines in a workshop, crew at a construction site, runways in airport, processing units in a computing environment are resources. Tasks are the operations in a manufacturing process, stages in a construction project, takeoffs and landings at an airport, execution of computer programs, etc. There is certain priority level, due date and starting time for every task. The objective is minimization of tasks completion with respect to due dates.

\section{Literature Survey}

The ideal grouping for n-employment and two machine issues is examined by Johnson (1954). Palmer (1965) has utilized a solitary practice strategy for make traverse minimization through the occupations organized in view of the slant guide and arranging in diminishing request valuable to $\mathrm{m}$ machine and $\mathrm{n}$ work stream shop game plan issues. Campbell et al. (1970) utilizing number of redundancies before it achieved the last outcome, extensively utilized and generally known as Campbell, Dudek and Smith heuristics (CDS) delayed the straightforward Johnson calculation. Gupta (1971) limited the finish time and the influence traverse by utilizing particular calculation by receiving an alternate methodology to acquire the incline to control, based on which the tending to of employments is finished in the stream shop climate. A model on the general handling time of the distinctive employments is produced by Nawaz et al. (1983). The activity was planned in light of the need of most noteworthy handling time. For minimization of make traverse they used a heuristic, which is generally known as NEH heuristics calculation. For the minimization of mean stream time alongside influence traverse in a stream to shop climate an unmistakable technique was produced by Nagar et al. (1996). They have utilized branch and bound strategy and the. Hereditary calculation to achieve the required goal. For taking care of the stream shop planning issue Nowicki and Smutnicki (1996) have actualized tabu pursuit. For taking care of the twomachine issue by limiting the make traverse Neppalli et al (1996) utilized the fundamental dynamic calculation. For estimation of heuristics which wassequenced for adaptable stream shop planning issues is finished by Jungwattanakit et al. (2005).A model utilizing due dates as requirements which was identified with single machine issues i.e.., past grouping models that are needy is created by Biskupand Herrmann (2008) and the inspiration driving this model isminimization ofpunishments which are accomplished where the demand isn't satisfied inside the due date. By considering an extensive size issue and settled using inherited estimation for the arranging of a lone stage and multi thing group plants nearby parallel units a transformative count was used by He and Hui (2008) in conclusion proposed the heuristics approach. A model was made by Eren and Guner, (2008) for a two-machine stream shop issue moving toward the idea of figuring out how to limit the aggregate finishing time and the make traverse. To limit the aggregate earliness and lateness Tseng and Liao, (2008) have considered $\mathrm{m}$-machine and $\mathrm{n}$-work stream shop planning issue by utilizing the molecule swarm streamlining method limiting the weighted earliness and delay according to the organization prerequisites. By utilizing an imagining air alongside a machine to complete the objective of enhancing delay for end of the activity. Wu and Zhou, (2008) have considered an imagining plan way to deal with get the key calendar of employments. Mosheiov and Sarig (2009) have considered a few cost factors, for example, earliness, delay, the most up to date due date request and number of postponed employments and so forth and booked a course of action of 
occupations through due dates, delay, delay, and other cost factors minimization. Cheng and Lin (2009) have considered a few strategies, for example, Johnson's principles, rundown of the composite occupations, idea of adjustment for stream shop booking issue by framing Artificial employments with the comparative sit out of gear time as that of the honest to goodness working machine which limits the influence traverse of the stream to shop issue. Wu and Lee (2009) have limited the aggregate finish time in different stream shop presenting the idea of learning. For achieving the ideal arrangement through minimization of the general stream time a technique was proposed $\mathrm{Li}$ et.al, (2009) which incorporates composite heuristics models albeit utilized for add up to stream time in variety stream shop condition and the heuristics strategy has worked extremely well in minimization of aggregate stream time. The occupations are to be dealt with in a particular succession. examination among the different heuristics calculations from the influence traverse to yield has made by Modrak et al. (2013).

\section{Simultaneous Scheduling Through Heuristic Algorithm}

The productivity of machines and ideal handling information are expanded by looking at the activity shop and stream shop booking issues. A few techniques have been considered in the present investigation. The minimization of make traverse is finished by separating into two occupations and sequencing them from left to right and appropriate toleft individually by utilizing Johnsons (1954) two-machine issue. Palmer (1965) is wanted to advance from low to high preparing circumstances in light of the processing of incline file. Campbell (1970) basic calculation will be valuable to acquire arrangement of expansive grouping issues without PCs by giving suitable answers for the $\mathrm{n}$ work, $\mathrm{m}$ machine sequencing issues by thinking about no passing. The paradigm is least passed time up to m-1 successions. In view of Heuristic Gupta (1971) has changed the Palmer's incline file by arranging $n$ things. Dannenbring (1977) team up the benefits of Palmers incline file and the Campbell strategies by building up the fast access system. The stage stream shop planning issue with the make span minimization model for $\mathrm{m}$ machines and $\mathrm{n}$ employments is created by Nawaz (1983). Ronconi (2004) has built up a Min Max (MM) calculation tending to stream shop makespan minimization issue by disregarding supports. In this work RA Heuristic calculation is adjusted to take care of concurrent booking issues in FMS condition.

\subsection{Rapid Access Heuristic (RAH)}

This is known as insertion algorithm for make span minimization. The procedure is highlighted below.

Step 1: - The jobs in the given job set is converted into two jobs by using the formulae given below

$\mathrm{Ti} \mathrm{A}=(\mathrm{m} * \mathrm{Ti} 1)+((\mathrm{m}-1) * \mathrm{Ti} 2)+((\mathrm{m}-2) * \mathrm{Ti} 3)+((\mathrm{m}-3) * \mathrm{Ti} 4$

Where $\mathrm{m}=$ no. of machines

$\mathrm{Ti} \mathrm{B}=(1 * \mathrm{Ti} 1)+(2 * \mathrm{Ti} 2)+(3 * \mathrm{Ti} 3)+(4 * \mathrm{Ti} 4)$

Step 2: - The Least Processing Time for each job is marked

- If the both the jobs are processed with same times, then take the first one as priority

Step 3: - The jobs is divided into two groups based on their processing time namely $\mathrm{U}, \mathrm{V}$

- $\quad \mathrm{U}$ group as follows (Ti A<Ti B)

- $\quad \mathrm{V}$ group as follows (Ti $\mathrm{A}>\mathrm{Ti} \mathrm{B})$

Step 4: - Sortthe jobs "U" as follows which considering least processing times and these processing times are arranged with minimum process time to maximum process time.
Step 5:- Sort the jobs "V" as follows with consideration of least processing time on each job and arranging these processing times from maximum processing time to minimum processing time.

Step 6: - During the assignment period in U group if the least processing times are same (or) Tie select the job with least processing time as first priority. In $\mathrm{V}$ group if the least processing time are Tie (or) equal select the job with max. total processing time as first priority. The corresponding optimal sequence is ' $U V$ '

Step 7: - The process is continued till the end of the jobs.

\section{FMS Description}

In this examination the FMS has designs appeared in Fig.1 Machines comprising Computer Numerical Controlled Machines (CNCs) each actualizing autonomous and confident apparatus magazine, one Automatic Pallet Changer (APC) and one Automatic Tool Changer (ATC).

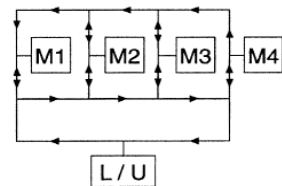

LAYOUT 1

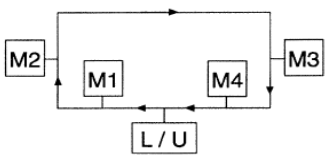

LAYOUT 3

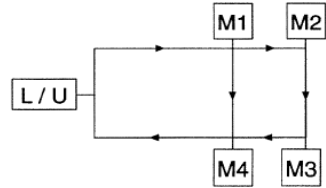

LAYOUT 2
Fig. 1 Example problems for Layout configurations

\subsection{Objective Function}

The primary point is make traverse improvement and the formulae utilized are demonstrated as follows:

Task fulfillment time $=\mathrm{O} i \mathrm{j}=\mathrm{Tij}+\mathrm{Pij}$

Job completion time

$\left(C_{i}\right)=\sum_{i=1}^{n} O_{i j}$

Makespan $=\max (\mathrm{C} 1, \mathrm{C} 2, \mathrm{C} 3 \ldots \mathrm{Cn})$

where $\mathrm{i}=\mathrm{job}, \mathrm{j}=$ operation, $\mathrm{Tij}=$ travelling time, $\mathrm{P} \mathrm{ij}=$ operation processing time

\subsection{Input Data}

The underlying information (i.e. voyaging time lattice) of Table 2 and Job sets of Bilge and Ulusoy (1995) are considered. For all the four designs, stack/empty stations to machines and separations between machines in meters is appeared in Data Table 2. The Ten employment sets in Table 1 each having max of eight distinctive occupation sets, machines and numbers with in the expansion is the handling time of certain activity on indicated machine. The heap/empty (L/U) station helps an inside for apportioning the parts not yet oversaw and as an arrangement community for parts finished as all vehicles begins at first from here. Excursions take after the most limited way between two focuses either between two machines or between a machine and the $\mathrm{L} / \mathrm{U}$ station. Acquisition of treks isn't permitted. The outings are called stacked or deadheading (purge) trips. The periods for the deadheading ventures 
are succession which are reliant until the point when the vehicle course is distinct.

\section{Vehicle Scheduling Methodology}

The activity grouping inferred by the RA heuristic calculation are utilized for planning of Jobs. The primary activities are orchestrated when AGVs make double outings i.e.., stacked excursion and dead heading and convey employments to the separate workstation. stacked excursion conveys a heap and deadheading trip where the vehicle moves to get a heap quickly after the

conveyance and the consequent assignments are influenced thinking about the vehicle to request at various workstations. The most punctual accessible circumstances of the AGVs are figured and the task is made if no vehicle is accessible and both AGVsare accessible undertaking is doled out. The asset use and the throughput are enhanced by allocating the procedure which will be done ahead of schedule to the vehicle which is sit out of gear and the vehicle is moved to get that activity which helps in holding up time decrease. The vehicle task procedure stream outline is given in Fig.2

\section{Simultaneous Scheduling Through Heuristic Algorithms}

The RA Heuristic Algorithm is implemented to the simultaneous scheduling problems. The basic input utilized to study this aspect.

\subsection{Simultaneous Scheduling-RA Heuristic Algorithm}

For implementation of RA Heuristic Algorithm, job set 1 and layout 4 are considered as an example. RA Heuristic Algorithm constructs jobs sequence in an iterative manner. The iterations are sustained till all jobs from the content list are positioned in the partial sequence.

The RA Heuristic is explained in the following steps for the job set 1:

Ex: Algorithm for Jobset-2 and Layout-1

\begin{tabular}{|l|l|l|l|l|l|l|}
\hline Job & 1 & 2 & 3 & 4 & 5 & 6 \\
\hline Ti1 & 10 & 0 & 10 & 0 & 10 & 10 \\
\hline Ti2 & 0 & 10 & 0 & 10 & 15 & 15 \\
\hline Ti3 & 0 & 0 & 20 & 15 & 0 & 12 \\
\hline Ti4 & 18 & 18 & 0 & 12 & 12 & 0 \\
\hline
\end{tabular}

For job-1

Ti A $=(m * T i 1)+((m-1) * T i 2)+((m-2) * \mathrm{Ti} 3)+((m 3) * \mathrm{Ti} 4)$

Here $\mathrm{m}=$ no. of machines $=4$

$=(4 * 10)+(3 * 0)+(2 * 0)+(1 * 18)=58$

Ti $\mathrm{B}=(1 * \mathrm{Ti} 1)+(2 * \mathrm{Ti} 2)+(3 * \mathrm{Ti} 3)+(4 * \mathrm{Ti} 4)$

$=(1 * 10)+(2 * 0)+(3 * 0)+(4 * 18)=82$

For job-2

$\mathrm{TiA}=(\mathrm{m} * \mathrm{Ti} 1)+((\mathrm{m}-1) * \mathrm{Ti} 2)+((\mathrm{m}-2) * \mathrm{Ti} 3)+((\mathrm{m}-3) * \mathrm{Ti} 4)$

Here $m=$ no. of machines $=4$

$=(4 * 0)+(3 * 10)+(2 * 0)+(1 * 18)=48$

Ti B $=(1 *$ Ti 1$)+(2 *$ Ti 2$)+(3 *$ Ti 3$)+(4 *$ Ti 4$)$

$=(1 * 0)+(2 * 10)+(3 * 0)+(4 * 18)=92$

For job-3

Ti $\mathrm{A}=(\mathrm{m} * \mathrm{Ti} 1)+((\mathrm{m}-1) * \mathrm{Ti} 2)+((\mathrm{m}-2) * \mathrm{Ti} 3)+((\mathrm{m}-3) * \mathrm{Ti} 4)$

Here $\mathrm{m}=$ no. of machines $=4$

$=(4 * 10)+(3 * 0)+(2 * 20)+(1 * 0)=80$

$\mathrm{Ti} \mathrm{B}=(1 * \mathrm{Ti} 1)+(2 * \mathrm{Ti} 2)+(3 * \mathrm{Ti} 3)+(4 * \mathrm{Ti} 4)$

$=(1 * 10)+(2 * 0)+(3 * 20)+(4 * 0)=70$
For job-4

$\mathrm{Ti} \mathrm{A}=(\mathrm{m} * \mathrm{Ti} 1)+((\mathrm{m}-1) * \mathrm{Ti} 2)+((\mathrm{m}-2) * \mathrm{Ti} 3)+((\mathrm{m}-3) * \mathrm{Ti} 4)$

Here $\mathrm{m}=$ no. of machines $=4$

$=(4 * 0)+(3 * 10)+(2 * 15)+(1 * 12)=72$

$\mathrm{Ti} \mathrm{B}=(1 * \mathrm{Ti} 1)+(2 * \mathrm{Ti} 2)+(3 * \mathrm{Ti} 3)+(4 * \mathrm{Ti} 4)$

$=(1 * 0)+(2 * 10)+(3 * 15)+(4 * 12)=113$

For job-5

Ti $\mathrm{A}=(\mathrm{m} * \mathrm{Ti} 1)+((\mathrm{m}-1) * \mathrm{Ti} 2)+((\mathrm{m}-2) * \mathrm{Ti} 3)+((\mathrm{m}-3) * \mathrm{Ti} 4)$

Here $\mathrm{m}=$ no. of machines $=4$

$=(4 * 10)+(3 * 15)+(2 * 0)+(1 * 12)=97$

$\mathrm{Ti} \mathrm{B}=(1 * \mathrm{Ti} 1)+(2 * \mathrm{Ti} 2)+(3 * \mathrm{Ti} 3)+(4 * \mathrm{Ti} 4)$

$=(1 * 10)+(2 * 15)+(3 * 0)+(4 * 12)=88$

For job -6

$\mathrm{Ti} \mathrm{A}=(\mathrm{m} * \mathrm{Ti} 1)+((\mathrm{m}-1) * \mathrm{Ti} 2)+((\mathrm{m}-2) * \mathrm{Ti} 3)+((\mathrm{m}-3) * \mathrm{Ti} 4)$

Here $\mathrm{m}=$ no. of machines $=4$

$=(4 * 10)+(3 * 15)+(2 * 12)+(1 * 0)=109$

$\mathrm{Ti} \mathrm{B}=(1 * \mathrm{Ti} 1)+(2 * \mathrm{Ti} 2)+(3 * \mathrm{Ti} 3)+(4 * \mathrm{Ti} 4)$

$=(1 * 10)+(2 * 15)+(3 * 12)+(4 * 0)=76$

\begin{tabular}{|l|l|l|l|l|l|l|}
\hline Job & 1 & 2 & 3 & 4 & 5 & 5 \\
\hline Ti A & 58 & 48 & 80 & 72 & 97 & 109 \\
\hline Ti B & 82 & 92 & 70 & 113 & 88 & 76 \\
\hline
\end{tabular}

Now Performing the Johnsons Algorithm

Mark the Least Processing Time for each job

$\begin{array}{llllll}\text { Ti A58 } & 48 & 80 & 72 & 97 & 10\end{array}$

Ti B82 $82 \quad 70 \quad 113 \quad 8876$

Based on their processing time jobs are divided into two groups namely $\mathrm{U}, \mathrm{V}$

$\mathrm{U}$ group as follows $(\mathrm{Ti} \mathrm{A}<\mathrm{Ti} \mathrm{B})=1,2,4$

$\mathrm{V}$ group as follows $(\mathrm{Ti} \mathrm{A}>=\mathrm{Ti} \mathrm{B})=3,5,6$

Sortthe jobs "U" as follows which considering least processing times and these processing times are arranged with minimum process time to maximum process time.

$$
\mathrm{U}=124
$$

Process time $=584872$

Arrangement $=485872$

$\mathrm{U}=214$

Sort the jobs "V" as follows with consideration of least processing time on each job and arranging these processing times from maximum processing time to minimum processing time

$$
\begin{aligned}
& \mathrm{V}=356 \\
& \text { Process time }=708876 \\
& \text { Arrangement }=887670 \\
& \mathrm{~V}=563
\end{aligned}
$$

The corresponding optimal sequence is ' $\mathrm{UV}$ '

$$
\text { Job: } \quad 214563
$$

Obtained optimal sequence is ' $U V$ ' make- span values is shown in table 3 .

Algorithm for job set 2 layout 1. From the table 3 it is observed that operation 3 on machine 1 is completed by 18 min. Hence $4^{\text {th }}$ operation will start after completion of $3^{\text {rd }}$ operation on machine 1 . In case of job set 2 and layout 1 operation 4 on machine 4 is completed by 44 min. Hence $1^{\text {st }}$ operation on machine 2 will start after completion of 4 operation on machine 4 . Similarly, no operation on the machine will start until the operation on the machine is completed. From the vehicle heuristic algorithm for first two operations $\mathrm{AGVs}$ are selected randomly in case of third operation $\mathrm{AGV}$ ' 1 ' is selected basing on the availability of AGV with mini- 
mum travel time this constraint will be taking care in the algorithm. For job set 2 and layout 1 the operational completion time (make span) is 172 .

\section{Results and Discussion}

Ten employment sets for four formats are utilized to create 82 illustration issues by producing different process times and handling groupings where Table 4 and Table 5 has issues whose ti/pi proportions are higher than and lower than 0.25 separately, which comprise of two vehicles and a code is intended for the case issues spoke to in the main segment. The digits that take after 1.1 address the movement set and the digit either 0 or 1 included as the last digit proposes the strategy times are duplicated or tripled and reduced to half in the two cases.

\section{Conclusions}

The optimal sequence of machines and AGVs are determined by using RA heuristic algorithm. Comparing with FCFS it is observed from Table 4 that 29 problems out of 40 give better results. Comparing with SPT 35 problems has given the better results (Nageswararao et al. 2017). 33 problems have given the better results when compared with LPT. It is observed from Table 5 that can be detected that from 1.4, 30 out of 42 problem has given the better results using RA when compared with FCFS, 42 problems gives better results when compared with SPT and LPT.

\section{Acknowledgments}

The authors greatly acknowledge the financial support from DSTSERB, Govt.of India (Sanction No: SB/EMEQ-501/2014) for carrying out This R \& D activity.

\section{References}

[1] Bilge, U., \& Ulusoy, G. (1995). A time window approach to simultaneous scheduling of machines and material handling system in a FMS. Operations Research, 43 (6), 1058-1070.

[2] Biskup, D., \& Herrmann, J. (2008). Single-machine scheduling against due dates with past-sequence-dependent setup times. European Journal of Operational Research, 191 (2), 587-592.

[3] Campbell, H.G, Dudek, R.A., \& Smith M.L. (1970). A Heuristic Algorithm for the $\mathrm{n}$ Job $\mathrm{m}$ Machine Sequencing Problem. Management Science, 16, B630-B637.

[4] Cheng, T. C. E., \& Lin, B. M. T. (2009). Johnson's rule, composite jobs and the relocation problem. European Journal of Operational Research, 192, 1008-10013.

[5] Dannenbring, D. G. (1977). An evaluation of flow shop sequencing heuristics. Management Science, 23(11), 1174-1182.

[6] Eren, T., \& Güner, E. (2008). A bicriterion flowshop scheduling with a learning effect. Applied Mathematical Modeling, 32, 17191733 .

[7] Gupta, J. N. D. (1971). A functional heuristic algorithm for the f1owshop scheduling problem. Operational Research, 22, 39-47.

[8] He, Y., \& Hui, C. W. (2008). A rule-based genetic algorithm for the scheduling of single-stage multi-product batch plants with parallel units. Computers and Chemical Engineering, 32, 30673083.

[9] Johnson, S.M. (1954). Optimal two-and-three-stage production schedules with set-up times included. Naval Research Logistic, 1, 61-68.

[10] Jungwattanakit, J., Reodecha, M., Chaovalitwongse, P., \& Werner, F. (2005). An evaluation of sequencing heuristics for flexible flowshop scheduling problems with unrelated parallel machines and dual criteria. Otto-von-Guericke-Universitat Magdeburg, 28(05), 123.

[11] Li, X., Wang, Q., \& Wu, C. (2009). Efficient composite heuristics for total flowtime minimization in permutation flow shops OMEGA, the International Journal of Management Science, 37 (1) $155-164$.
[12] Modrak, V., Semanco, P., \& Kulpa, W. (2013). Performance Measurement of Selected Heuristic Algorithms for Solving Scheduling Problems. In: 11th International Symposium on Applied Machine Intelligence and Informatics, 205-209.

[13] Mosheiov, G., \& Sarig, A. (2009). Due-Date Assignment on Uniform Machines. European Journal of Operational Research, 193(1), 49-58.

[14] Nagar, A., Heragu, S. S., \& Haddock, J. (1996). A combined branch and bound and genetic algorithm based approach for a flow shop-scheduling problem. Annals Operation Research, 63, 397414.

[15] Nageswararao, M., Narayanarao, K., \& Rangajanardhana, G. (2017). Integrated scheduling of machines and agvs in fms by using dispatching rules. Journal of production engineering, 20 (1), 75-84.

[16] Nawaz, M., Enscore Jr. E., \& Ham, I. (1983). A heuristic algorithm for the m-machine, n-job flow-shop sequencing problem. OMEGA, 11(1), 91-95.

[17] Neppalli, V. R., Chen, C. L., \& Gupta, J. N. D. (1996). Genetic algorithms for the two stage criteria flowshop problem. European Journal of Operational Research, 95(2), 356-373.

[18] Nowicki, E., \& Smutnicki, C. (1996). A fast tabu search algorithm for the permutation flowshop problem. European Journal of Operational Research, 91(1), 160-175.

[19] Palmer, D.S. (1965). Sequencing jobs through a multistage process in the minimum total time: A quick method of obtaining a nearoptimum. Operational Research, 16, 101-107.

[20] Ronconi, D. P. (2004). A note on constructive heuristics for the flowshop problem with blocking. International Journal of Production Economics, 87(1), 39-48.

[21] Stecke, K.E., \& Solberg, J.J. (1981).Loading and control policies for a flexible manufacturing-system. International Journal of Production Research, 19 (5), 481 - 490.

[22] Tseng, C. T., \& Liao, C. J. (2008). A discrete particle swarm optimization for lot-streaming flowshop scheduling problem. European Journal of Operational Research, 191 (2), 360-373.

[23] Wu, C.C., \& Lee, W.C. (2009). A note on the total completion time problem in a permutation flow shop with a learning effect. European Journal of Operational Research, 192, 343-347.

[24] Wu, X., \& Zhou, X. (2008). Stochastic scheduling to minimize expected maximum lateness. European Journal of Operational Research, 190 (1), 103-1

\section{Annexure}

Table 1 Data for the Job Sets Used in Example Problems

\begin{tabular}{|c|c|}
\hline $\begin{array}{l}\text { JobSet-1 } \\
\text { Job 1: Ml(8); M2(16); M4(12) } \\
\text { Job 2: Ml(20); M3(10); M2(18) } \\
\text { Job 3: M3(12); M4(8); Ml(15) } \\
\text { Job 4: M4(14); M2(18) } \\
\text { Job 5: M3(10); Ml(15) }\end{array}$ & $\begin{array}{l}\text { JobSet-2 } \\
\text { Job 1: M1(10); M4(18) } \\
\text { Job 2: M2(10); M4(18) } \\
\text { Job 3: M1(10); M3(20); } \\
\text { Job 4: M2(10); M3(15); M4(12) } \\
\text { Job 5: M1(10); M2(15); M4(12) } \\
\text { Job 6: M1(10); M2(15); M3(12) }\end{array}$ \\
\hline $\begin{array}{l}\text { JobSet-3 } \\
\text { Job 1:Ml(16); M3(15) } \\
\text { Job 2:M2(18); M4(15) } \\
\text { Job 3:Ml(20); M2(10) } \\
\text { Job 4:M3(15); M4(10) } \\
\text { Job } \\
\text { 5:Ml(8);M2(10);M3(15);M4(17) } \\
\text { Job 6: } \\
\text { M2(10);M3(15);M4(8);Ml(15 }\end{array}$ & $\begin{array}{l}\text { JobSet-4 } \\
\text { Job1: M4(11); Ml(10); M2(7) } \\
\text { Job2: M3(12); M2(10); M4(8) } \\
\text { Job3: M2(7); M3(10); Ml(9); M3(8) } \\
\text { Job4: M2(7); M4(8); Ml(12);M2(6) } \\
\text { Job5:M1(9);M2(7);M4(8);M2(10);M3(8) }\end{array}$ \\
\hline $\begin{array}{l}\text { JobSet-5 } \\
\text { Job 1: Ml(6);M2(12);M4(9) } \\
\text { Job 2: Ml(18);M3(6); M2(15) } \\
\text { Job 3: M3(9);M4(3);Ml(12) } \\
\text { Job 4: M4(6);M2(15) } \\
\text { Job 5: M3(3);Ml(9) }\end{array}$ & $\begin{array}{l}\text { JobSet-6 } \\
\text { Job 1: M1(9); M2(11); M4(7) } \\
\text { Job 2: M1(19); M2(20); M4(13) } \\
\text { Job 3: M2(14); M3(20); M4(9) } \\
\text { Job 4: M2(14); M3(20); M4(9) } \\
\text { Job 5: M1(11); M3(16); M4(8) } \\
\text { Job 6: M1(10); M3(12); M4(10) }\end{array}$ \\
\hline $\begin{array}{l}\text { JobSet-7 } \\
\text { Job 1: Ml(6); M4(6) } \\
\text { Job 2: M2(11); M4(9) } \\
\text { Job 3: M2(9); M4(7) } \\
\text { Job 4: M3(16); M4(7) } \\
\text { Job 5: M1(9); M3(18) } \\
\text { Job 6: M2(13); M3(19); M4(6) } \\
\text { Job 7: M1(10); M2(9); M3(13) } \\
\text { Job 8: M1(11); M2(9); M4(8) }\end{array}$ & $\begin{array}{l}\text { JobSet-8 } \\
\text { Job 1: M2(12); M3(21);M4(11) } \\
\text { Job 2: M2(12); M3(21);M4(11) } \\
\text { Job 3: M2(12); M3(21);M4(11) } \\
\text { Job 4: M2(12); M3(21);M4(11) } \\
\text { Job 5: M1(10); M2(14);M3(18);M4(9) } \\
\text { Job 6: M1(10);M2(14); M3(18);M4(9) }\end{array}$ \\
\hline $\begin{array}{l}\text { JobSet-9 } \\
\text { Job 1: M3(9);Ml(12);M2(9);M4(6) } \\
\text { Job 2: M3(16);M2(11); M4(9) } \\
\text { Job 3: M1(21); M2(18); M4(7) } \\
\text { Job 4: M2(20); M3(22); M4(11) }\end{array}$ & $\begin{array}{l}\text { JobSet-10 } \\
\text { Job1:M1(11);M3(19);M2(16);M4(13) } \\
\text { Job2: M2(21);M3(16); M4(14) } \\
\text { Job3:M3(8); M2(10); M1(14); M4(9) } \\
\text { Job4: M2(13); M3(20); M4(10) }\end{array}$ \\
\hline
\end{tabular}


Table 2 Travel time matrix for this particular problem

\begin{tabular}{|l|l|l|l|l|l|}
\hline \multicolumn{7}{|l|}{ Layout-1 } \\
\hline $\begin{array}{l}\text { From/ } \\
\text { To }\end{array}$ & $\mathrm{L} /$ & $\mathrm{M}$ & $\mathrm{M}$ & $\mathrm{M}$ & $\mathrm{M}$ \\
1 & 2 & 3 & 4 \\
\hline L/U & 0 & 6 & 8 & 10 & 12 \\
\hline M1 & 12 & 0 & 6 & 8 & 10 \\
\hline M2 & 10 & 6 & 0 & 6 & 8 \\
\hline M3 & 8 & 8 & 6 & 0 & 6 \\
\hline M4 & 6 & 10 & 8 & 6 & 0 \\
\hline
\end{tabular}

\begin{tabular}{|l|l|l|l|l|l|}
\hline \multicolumn{2}{|l|}{ Layout-2 } \\
\hline From/ & $\mathrm{L} /$ & $\mathrm{M}$ & $\mathrm{M}$ & $\mathrm{M}$ & $\mathrm{M}$ \\
To & $\mathrm{U}$ & 1 & 2 & 3 & 4 \\
\hline $\mathrm{L} / \mathrm{U}$ & 0 & 4 & 6 & 8 & 6 \\
\hline $\mathrm{M} 1$ & 6 & 0 & 2 & 4 & 2 \\
\hline $\mathrm{M} 2$ & 8 & 12 & 0 & 2 & 4 \\
\hline $\mathrm{M} 3$ & 6 & 10 & 12 & 0 & 2 \\
\hline M4 & 4 & 8 & 10 & 12 & 0 \\
\hline
\end{tabular}

\begin{tabular}{|c|c|c|c|c|c|}
\hline \multicolumn{6}{|c|}{ Layout-3 } \\
\hline From/ & $\mathrm{L} /$ & M & M & $M$ & $\mathrm{M}$ \\
\hline To & $\mathrm{U}$ & 1 & 2 & 3 & 4 \\
\hline $\mathrm{L} / \mathrm{U}$ & 0 & 2 & 4 & 10 & 12 \\
\hline M1 & 12 & 0 & 2 & 8 & 10 \\
\hline M2 & 10 & 12 & 0 & 6 & 8 \\
\hline M3 & 4 & 6 & 8 & 0 & 2 \\
\hline M4 & 2 & 4 & 6 & 12 & 0 \\
\hline
\end{tabular}

\begin{tabular}{|l|l|l|l|l|l|}
\hline \multicolumn{2}{|l|}{ Layout-4 } \\
\hline From/ & $\mathrm{L} /$ & $\mathrm{M}$ & $\mathrm{M}$ & $\mathrm{M}$ & $\mathrm{M}$ \\
To & $\mathrm{U}$ & 1 & 2 & 3 & 4 \\
\hline L/U & 0 & 4 & 8 & 10 & 14 \\
\hline $\mathrm{M} 1$ & 18 & 0 & 4 & 6 & 10 \\
\hline $\mathrm{M} 2$ & 20 & 14 & 0 & 8 & 6 \\
\hline $\mathrm{M} 3$ & 12 & 8 & 6 & 0 & 6 \\
\hline M4 & 14 & 14 & 12 & 6 & 0 \\
\hline
\end{tabular}

Table 3 shows operation scheduling of through RAPID ACCESS heuristic

\begin{tabular}{|c|c|c|c|c|c|c|c|c|c|c|c|c|c|}
\hline O. No & M.No & V.No & VPL & POMN & VRT & POCT & $\begin{array}{l}\text { VET } \\
=\mathrm{VRT}+\mathrm{TRT} 1 \\
(4 \text { to } 5)\end{array}$ & $\operatorname{Max}(7,8)$ & $\begin{array}{l}\text { VLT } \\
=\mathrm{VET}+\mathrm{TRT} 2 \\
(5 \text { to } 2)\end{array}$ & MRT & $\operatorname{Max}(10,11)$ & $\begin{array}{l}\text { Process } \\
\text { Time }\end{array}$ & $\begin{array}{l}\text { Make } \\
\text { Span }\end{array}$ \\
\hline (1) & (2) & (3) & (4) & (5) & (6) & (7) & $(8)$ & (9) & $(10)$ & (11) & (12) & (13) & (14) \\
\hline 3 & 2 & 1 & 0 & 0 & 0 & 0 & 0 & 0 & 8 & 0 & 8 & 10 & 18 \\
\hline 4 & 4 & 2 & 0 & 2 & 0 & 18 & 8 & 18 & 26 & 0 & 26 & 18 & 44 \\
\hline 1 & 1 & 1 & 2 & 0 & 8 & 0 & 18 & 18 & 24 & 0 & 24 & 10 & 34 \\
\hline 2 & 4 & 1 & 1 & 1 & 24 & 34 & 24 & 34 & 44 & 44 & 44 & 18 & 62 \\
\hline 7 & 2 & 2 & 4 & 0 & 26 & 0 & 32 & 32 & 40 & 18 & 40 & 10 & 50 \\
\hline 8 & 3 & 2 & 2 & 2 & 40 & 50 & 40 & 50 & 56 & 0 & 56 & 15 & 71 \\
\hline 9 & 4 & 1 & 4 & 3 & 44 & 71 & 50 & 71 & 77 & 62 & 77 & 12 & 89 \\
\hline 10 & 1 & 2 & 3 & 0 & 56 & 0 & 64 & 64 & 70 & 34 & 70 & 10 & 80 \\
\hline 11 & 2 & 2 & 1 & 1 & 70 & 80 & 70 & 80 & 86 & 50 & 86 & 15 & 101 \\
\hline 12 & 4 & 1 & 4 & 2 & 77 & 101 & 85 & 101 & 109 & 89 & 109 & 12 & 121 \\
\hline 13 & 1 & 2 & 2 & 0 & 86 & 0 & 96 & 96 & 102 & 80 & 102 & 10 & 112 \\
\hline 14 & 2 & 2 & 1 & 1 & 102 & 112 & 102 & 112 & 118 & 101 & 118 & 15 & 133 \\
\hline 15 & 3 & 1 & 4 & 2 & 109 & 133 & 117 & 133 & 139 & 71 & 139 & 12 & 151 \\
\hline 5 & 1 & 2 & 2 & 0 & 118 & 0 & 128 & 128 & 134 & 112 & 134 & 10 & 144 \\
\hline 6 & 3 & 2 & 1 & 1 & 134 & 144 & 134 & 144 & 152 & 151 & 152 & 20 & 172 \\
\hline
\end{tabular}

O. No: Operations Number M. No: Machine Number. V. No: Vehicle Number

VPL: Vehicle Previous Location POMN: Previous Operations Machine Number

VRT: Vehicle Ready Time Time

VET: Vehicle Empty Trip chine Ready Time

POCT: Previous Operation Completion

VLT: Vehicle Loaded Trip MRT: Ma-

\begin{tabular}{|c|c|c|c|c|c|}
\hline Job. No & $t / p$ & FCFS & SPT & LPT & RA \\
\hline 1.1 & 0.59 & 173 & 193 & 177 & 159 \\
\hline 2.1 & 0.61 & 158 & 158 & 177 & 172 \\
\hline 3.1 & 0.59 & 202 & 224 & 198 & 211 \\
\hline 4.1 & 0.91 & 263 & 267 & 264 & 260 \\
\hline 5.1 & 0.85 & 148 & 164 & 148 & 147 \\
\hline 6.1 & 0.78 & 231 & 240 & 227 & 225 \\
\hline 7.1 & 0.78 & 195 & 210 & 201 & 194 \\
\hline 8.1 & 0.58 & 261 & 261 & 266 & 261 \\
\hline 9.1 & 0.61 & 270 & 277 & 268 & 263 \\
\hline 10.1 & 0.55 & 308 & 308 & 310 & 312 \\
\hline 1.2 & 0.47 & 143 & 173 & 165 & 141 \\
\hline 2.2 & 0.49 & 124 & 124 & 130 & 128 \\
\hline 3.2 & 0.47 & 162 & 188 & 160 & 175 \\
\hline 4.2 & 0.73 & 217 & 223 & 224 & 216 \\
\hline 5.2 & 0.68 & 118 & 144 & 131 & 112 \\
\hline 6.2 & 0.54 & 180 & 169 & 165 & 154 \\
\hline 7.2 & 0.62 & 149 & 160 & 149 & 144 \\
\hline 8.2 & 0.46 & 181 & 181 & 198 & 181 \\
\hline 9.2 & 0.49 & 250 & 249 & 244 & 239 \\
\hline 10.2 & 0.44 & 290 & 288 & 287 & 273 \\
\hline 1.3 & 0.52 & 145 & 175 & 167 & 143 \\
\hline 2.3 & 0.54 & 130 & 130 & 136 & 130 \\
\hline 3.3 & 0.51 & 160 & 190 & 162 & 173 \\
\hline 4.3 & 0.8 & 233 & 237 & 230 & 226 \\
\hline 5.3 & 0.74 & 120 & 146 & 133 & 114 \\
\hline 6.3 & 0.54 & 182 & 171 & 167 & 156 \\
\hline 7.3 & 0.68 & 155 & 166 & 151 & 150 \\
\hline 8.3 & 0.5 & 183 & 183 & 200 & 183 \\
\hline 9.3 & 0.53 & 252 & 251 & 246 & 241 \\
\hline 10.3 & 0.49 & 293 & 294 & 293 & 279 \\
\hline 1.4 & 0.74 & 189 & 207 & 189 & 191 \\
\hline
\end{tabular}




\begin{tabular}{|c|c|c|c|c|c|}
\hline 2.4 & 0.77 & 174 & 174 & 174 & 172 \\
\hline 3.4 & 0.74 & 220 & 250 & 212 & 225 \\
\hline 4.4 & 1.14 & 301 & 301 & 298 & 298 \\
\hline 5.4 & 1.06 & 171 & 189 & 171 & 171 \\
\hline 6.4 & 0.78 & 249 & 252 & 237 & 237 \\
\hline 7.4 & 0.97 & 217 & 242 & 151 & 210 \\
\hline 8.4 & 0.72 & 285 & 285 & 200 & 285 \\
\hline 9.4 & 0.76 & 292 & 311 & 290 & 285 \\
\hline 10.4 & 0.69 & 350 & 350 & 345 & 348 \\
\hline
\end{tabular}

Table 5 Performance evaluation for $\mathrm{t} / \mathrm{p}<0.25$

\begin{tabular}{|c|c|c|c|c|c|}
\hline Job.No & $t / p$ & FCFS & SPT & LPT & RA \\
\hline 1.10 & 0.15 & 207 & 248 & 252 & 207 \\
\hline 2.10 & 0.15 & 217 & 217 & 225 & 185 \\
\hline 3.10 & 0.15 & 257 & 327 & 282 & 255 \\
\hline 4.10 & 0.15 & 303 & 328 & 317 & 277 \\
\hline 5.10 & 0.21 & 152 & 190 & 187 & 154 \\
\hline 6.10 & 0.16 & 304 & 281 & 297 & 272 \\
\hline 7.10 & 0.19 & 231 & 240 & 264 & 213 \\
\hline 8.10 & 0.14 & 338 & 338 & 347 & 332 \\
\hline 9.10 & 0.15 & 390 & 367 & 359 & 324 \\
\hline 10.10 & 0.14 & 452 & 429 & 444 & 398 \\
\hline 1.20 & 0.12 & 194 & 238 & 246 & 197 \\
\hline 2.20 & 0.12 & 194 & 194 & 206 & 167 \\
\hline 3.20 & 0.12 & 241 & 311 & 270 & 241 \\
\hline 4.20 & 0.12 & 285 & 312 & 298 & 248 \\
\hline 5.20 & 0.17 & 142 & 180 & 184 & 143 \\
\hline 6.20 & 0.12 & 292 & 260 & 284 & 251 \\
\hline 7.20 & 0.15 & 212 & 218 & 249 & 188 \\
\hline 8.20 & 0.11 & 306 & 319 & 334 & 306 \\
\hline 9.20 & 0.12 & 380 & 355 & 347 & 309 \\
\hline 10.20 & 0.11 & 445 & 423 & 439 & 388 \\
\hline 1.30 & 0.13 & 195 & 239 & 247 & 196 \\
\hline 2.30 & 0.13 & 197 & 197 & 209 & 170 \\
\hline 3.30 & 0.13 & 240 & 312 & 271 & 240 \\
\hline 4.30 & 0.13 & 292 & 317 & 301 & 255 \\
\hline 5.30 & 0.18 & 141 & 181 & 183 & 143 \\
\hline 6.30 & 0.24 & 296 & 261 & 285 & 252 \\
\hline 7.30 & 0.17 & 215 & 221 & 250 & 191 \\
\hline 8.30 & 0.13 & 307 & 320 & 335 & 307 \\
\hline 9.30 & 0.13 & 381 & 356 & 348 & 310 \\
\hline 10.30 & 0.12 & 448 & 426 & 442 & 391 \\
\hline 1.40 & 0.18 & 213 & 255 & 254 & 213 \\
\hline 2.41 & 0.13 & 307 & 307 & 319 & 267 \\
\hline 3.40 & 0.18 & 261 & 330 & 282 & 258 \\
\hline 3.41 & 0.12 & 370 & 476 & 411 & 310 \\
\hline 4.41 & 0.19 & 434 & 471 & 451 & 393 \\
\hline 5.41 & 0.18 & 218 & 269 & 270 & 222 \\
\hline 6.40 & 0.19 & 310 & 288 & 299 & 275 \\
\hline 7.40 & 0.24 & 239 & 251 & 270 & 221 \\
\hline 7.41 & 0.16 & 329 & 344 & 385 & 224 \\
\hline 8.40 & 0.18 & 343 & 343 & 349 & 339 \\
\hline 9.40 & 0.19 & 396 & 379 & 370 & 325 \\
\hline 10.40 & 0.17 & 466 & 445 & 455 & 415 \\
\hline
\end{tabular}

